\title{
SENAM TERA UNTUK MENURUNKAN TEKANAN DARAH LANSIA DI UPT PELAYANAN SOSIAL LANJUT USIA BINJAI
}

\author{
Resmi Pangaribuan ${ }^{1}$ Khairunnisa Batubara ${ }^{2}$ \\ Akademi Keperawatan Kesdam I/Bukit Barisan Medan \\ resmi.pangaribuan131417@gmail.com. ${ }^{1}{ }^{1}$ khairunnisa.batubara15@gmail.com ${ }^{2}$
}

\begin{abstract}
ABSTRAK
Pendahuluan: Lanjut usia cenderung mengalami masalah kesehatan oleh penurunan fungsi organ tubuh akibat proses penuaan. Sekitar 64\% lansia berusia 60-74 tahun akan mengalami peningkatan tekanan darah. Pada usia lanjut umumnya memiliki tingkat kesegaran jasmani yang rendah, terutama pada komponen daya tahan kardio, respiratori dan kekuatan otot. Hal tersebut dapat dicegah dengan melakukan latihan fisik yang baik dan benar. Senam lansia sangat penting untuk para lanjut usia untuk menjaga kesehatan tubuh mereka seperti senam tera. Senam tera merupakan suatu latihan yang melatih fisik, mental dan juga dapat memperbaiki dan meningkatkan kondisi serta fungsi jantung dan peredaran darah, serta mengontrol hipertensi. Metode: kegiatan yang digunakan dalam program pengabdian masyarakat ini berupa penyuluhan dan demonstrasi senam tera untuk menurunkan tekanan darah (Hipertensi) di UPT Pelayanan Sosial Lanjut Usia Binjai. Hasil: Lansia yang mengikuti kegiatan penyuluhan dan demonstrasi ini memahami tentang cara menurunkan tekanan darah tanpa obat dengan cara melakukan senam tera dan lansia mampu melakukan kembali senam yang dia jarkan. Hasil yang diperoleh setelah melakukan kegiatan tersebut pada pengetahuan lansia menunjukkan $65 \%$ lansia mau menerapkan senam hipertensi di wisma (rumah yang disediakan oleh UPT). Kesimpulan: Kegiatan ini dapat meningkatkan pengetahuan tentang senam tera sebagai upaya menurunkan tekanan darah pada hipertensi
\end{abstract}

Kata kunci: Edukasi, hipertensi, senam tera, lansia.

\begin{abstract}
Introduction: Elderly people experience health problems due to decreased organ function due to the aging process. Approximately 64\% of elderly aged 60-74 years will experience an increase in blood pressure. Elderly people generally have a low level of physical fitness, especially in the components of cardio, respiratory, and muscle strength endurance. This can be done by doing good and correct physical exercise. Elderly gymnastics is very important for the elderly to maintain their body health like tera gymnastics. Tera gymnastics is an exercise that trains physically, mentally and can also improve and improve the condition and function of the heart and blood circulation, as well as control hypertension. Methods: the activities used in this community service program are in the form of counseling and demonstration of calibration exercises to reduce blood pressure (hypertension) at the Binjai Elderly Social Service UPT. Results: The elderly who participated in this counseling and demonstration understood how to lower blood pressure without medication by doing tera exercises and the elderly were able to do the exercises that he taught. The results obtained after carrying out these activities on the knowledge of the elderly showed that $65 \%$ of the elderly were willing to apply hypertension exercise at the Wisma (the house provided by the UPT).
\end{abstract}

Keywords: Education, Hypertension, Tera gymnastics, the elderly 


\section{PENDAHULUAN}

Populasi lansia rata-rata menderita kemerosotan tingkat kesehatan dan sering merasakan kemunduran fungsi tubuh dikarenakan sudah berumur. Usia lanjut seringnya kekuatan jasmani menurun terutama daya tahan tubuh, jumlah pernafasan dan kira-kira 64\% lansia berusia 60-74 tahun (M. Noor Ifansyah, Herawati, 2015). Hal tersebut dapat dicegah dengan melakukan latihan fisik yang baik dan benar. Adapun aspek yang sangat menentukan tingkat kemandirian pada usia lanjut adalah keadaan mental, karena pada usia lanjut sering mengalami apa yang disebut demensia yaitu kemunduran dalam fungsi berfikir (Sudjana et al., 2015).

(Kurniasih \& Setiawan, 2013) menyatakan bahwa hipertensi merupakan suatu kondisi medis dimana orang yang tekanan darahnya meningkat diatas normal yaitu 140/90 mmHg dan dapat mengalami resiko kesakitan (mordibitas) bahkan kematian (mortalitas). Hipertensi merupakan salah satu penyakit kronis yang menyerang banyak orang di berbagai belahan dunia (Guèze \& Napitupulu, 2016).

Lanjut usia seringnya mengalami kenaikan tekanan darah sistolik (isolated systolic hypertention) dikarenakan kondisi aterosklorosis mengakibatkan hilangnya kelunakan pada pembuluh arteri yang besar (Kowalak, 2016). Hipertensi pada lansia terjadi karena pembuluh darah yang terjadi lentur dan elastik akan mengeras dan kaku, sehingga pembuluh darah tidak mampu untuk memasok kebutuhan aliran darah ke setiap organ (Mustofa et al., 2020). Senam dapat meningkatkan aktivitas metabolisme tubuh dan kebutuhan oksigen. Jenis latihan fisik yang dapat dilakukan oleh lansia adalah senam. Senam yang dilakukan pada lansia menjadi berguna bagi para lanjut usia untuk menjaga kesehatan tubuh para lansia seperti senam tera (Iswahyuni, 2017). Senam tera ialah suatu latihan yang melatih fisik, mental dan juga dapat memperbaiki dan meningkatkan kondisi serta fungsi jantung dan peredaran darah, serta mengontrol hipertensi (Tahun \& Ratulangi, 2020). Penelitian (Eviyanti et al., 2021) didapatkan $\mathrm{p}<0,05$, yang berarti $\mathrm{Ha}$ diterima dan Ho ditolak, dapat disimpulkan bahwa Adanya Pengaruh Senam Lansia Terhadap Penurunan tekanan. Berdasarkan penelitian yang dilakukan oleh (Eriyanti et al., 2016) menyatakan bahwa senam tera efektif membuat tekanan darah pada lansia menurun dengan kejadian hipertensi di Posyandu Lansia Kelurahan Pabelan Kartasura diperoleh hasil nilai tekanan darah signifikan.

Berdasarkan data (Kemenkes RI, 2019) World Health Organization menyatakan penderita hipertensi diperkirakan mencapai 1 milyar di dunia, dan dua per tiga 
diantaranya berada di negara berkembang. Angka tesebut kian hari kian mengkawatirkan yaitu sebanyak 972 juta (26\%) orang dewasa di dunia menderita hipertensi. Angka ini terus minngkat tajam, dan dipresdiksi pada tahun 2025 sekitar $29 \%$ orang dewasa di seluruh dunia menderita hipertensi.

\section{METODE}

Berdasarkan pendahuluan yang dilakukan peneliti di UPT pelayanan sosial lanjut usia Binjai di peroleh data jumlah pasien di UPT pelayanan sosial lanjut usia Binjai sebanyak 176 jiwa yang terdiri dari 90 pasien perempuan dan 86 laki-laki. Dari hasil observasi terdapat 32 orang lansia yang terdiagnosis Hipertensi. Dari 32 orang lansia diatas dilakukan wawancara kepada 8 orang lansia dan yang mengalami Hipertensi dengan gangguan pemenuhan aktivitas, ada 4 orang dari lansia tersebut mengatakan jarang mengikuti senam dan belum mengerti dengan senam yang dilakukan sehingga jarang mengikuti senam tersebut. Penatalaksanaan yang dilakukan pemberian terapi farmakologi berupa obat Hipertensi. Dari fenomena tersebut penulis tertarik untuk melakukan pengabdian masyrakat yaitu senam Tera untuk menurunkan tekanan darah pada lansia di UPT Pelayanan Sosial Usia Lanjut Binjai.

Sasaran pada pengabdian masyarakat ini adalah para usia lanjut yang menderita tekanan darah tinggi (Hipertensi)

Luaran pada pengabdian masyarakat ini adalah senam tera sebagai terapi komplementer (pendampingan) yang bertujuan untuk menurunkan tekanan darah.

Aktivitas pengabdian masyarakat ini dilaksanakan pada bulan Januari 2021. Pelaksanaan kegiatan pengabdian masyarakat ini dilakukan di salah satu Unit Pelayanan Terpadu Lansia di Unit kerja Dinas Sosial Medan yaitu UPT Pelayanan Sosial Lanjut Usia Binjai. Sasaran pelaksanaan kegiatan ini adalah lansia yang mengalami Hipertensi sebanyak 32 orang. Lama pelaksanaan ini adalah 2 minggu setiap hari Selasa, Rabu dan hari Kamis (seminggu). Lama pelaksanaan setiap kali kegiatan adalah 50 menit. Kegiatan pengabdian masyarakat ini dilakukan dimulai dari perijinan, pelaksanaan dan evaluasi kegiatan selama dua minggu. Pelaksanaan senam tera dilakukan selama satu minggu berturut-turut kepada lansia di UPT Pelayanan Sosial Lanjut Usia Binjai. Metode dan media yang digunakan dalam pemecahan masalah yang dilakukan pada kegiatan ini adalah dengan 
menggunakan metode ceramah, simulasi dengan senam tera dan gerakan. Alat bantu media yaitu leafleat, clip chart, alat pengukur tekanan darah (stetoskop, tensi meter, buku catatan dan pena), serta video senam tera. Media pembelajaran merupakan media yang digunakan untuk membantu merangsang pikiran, perasaan, kemampuan dan perhatian seseorang dalam proses belajar (Pangaribuan \& Nurleli, 2020).

\section{HASIL PEMBAHASAN}

\section{Hasil}

Kegiatan pengabdian masyarakat berupa edukasi tentang Hipertensi dengan senam tera dalam upaya menurunkan tekanan darah tinggi yang dilaksanakan di UPT Pelayanan Sosial Lanjut Usia Binjai pada Januari 2021. Peserta kegiatan edukasi Hipertensi dengan senam tera dalam upaya menurunkan tekanan darah tinggi dihadiri oleh 32 orang lansia. Kegiatan ini dimulai pukul 08.00-08.50 wib dilakukan senam tera dan penyuluhan dilakukan di Wisma lansia yang mengalami hipertensi satu hari sebelum pelaksanaan senam tera. Kegiatan ini diawali dengan evaluasi pengetahuan tentang Hipertensi kepada lansia sebagai peserta kegiatan. Tahap berikutnya penyuluhan dengan metode ceramah dengan menggunakan alat bantu media berupa pemutaran video, alat pengukur tekanan darah (stetoskop, tensi meter, buku catatan dan pena). Setelah tahapan ini selesai dilakukan evaluasi pada peserta penyuluhan untuk menilai pengetahuan tentang Hipertensi dan Senam Tera dalam upaya menurunkan tekanan darah. Kegiatan lainnya adalah pembagian leafleat yaitu berisi informasi kesehatan dan dibagikan kepada setiap lansia yang terdiagnosis Hipertensi dan dalam pemeriksaan mengalami kenaikan tekanan darah. Selanjutnya pemasangan clipchart/ poster penyuluhan.

\section{Kegiatan pengabdian masyarakat}

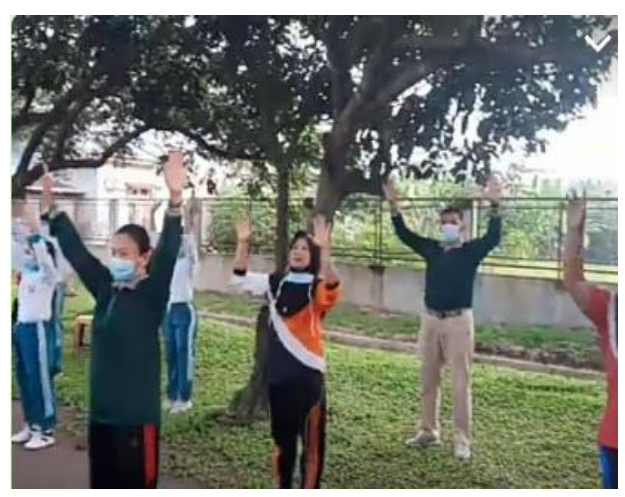


Gambar 1. Memberikan contoh gerakan senam tera
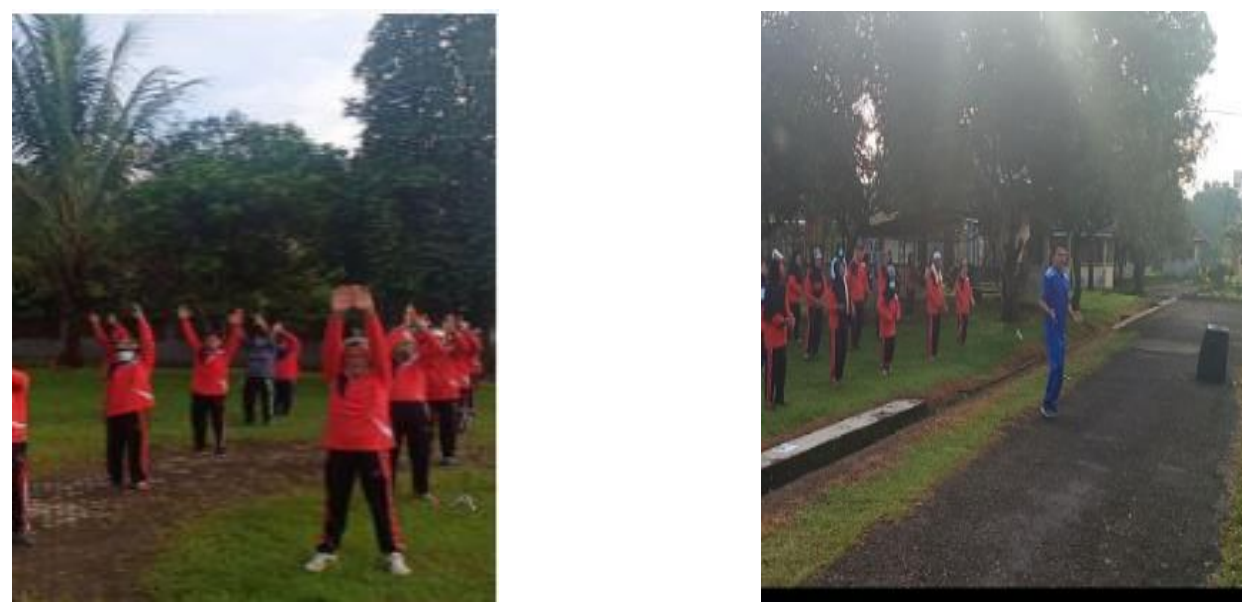

Gambar 2. Lansia mengikuti gerakan senam tera

Kegiatan ini bertujuan untuk memberikan informasi, pengetahuan serta keterampilan bagi lansia. Pengetahuan yang baik tentang kesehatan berhubungan dengan kebiasaan, life stile dan perilaku hidup sehat lansia. Menurut (Notoadmodjo, 2012), evaluasi tingkat pengetahuan yang berkaitan dengan kemampuan untuk melakukan justifikasi atau penilaian terhadap suatu materi dan merupakan domain yang sangat penting. Evaluasi ini dilakukan untuk mengukur keberhasilan kegiatan edukasi tentang hipertensi dilakukan dengan 3 (tiga) jenis evaluasi yaitu: 1. Evaluasi awal, dilakukan dengan memberikan pertanyaan lisan pada peserta kegiatan tentang materi Hipertensi dan senam tera. Hasil dari evaluasi ini berupa skor hasil pengetahuan dan keterampilan sebelum dilakukan intervensi penyuluhan dengan menggunakan instrument berupa checklist yang diisi oleh 3 (tiga) orang tim pelaksana kegiatan. 2. Evaluasi proses, evaluasi ini mencakup pengamatan secara langsung minat dan motivasi peserta kegiatan dalam berpartisipasi pada kegiatan penyuluhan melalui respon pertanyaan-pertanyaan dan interaksi siswa dengan tim pelaksana selama pelaksanaan kegiatan. 3. Evaluasi akhir, dilakukan dengan memberikan kesempatan kepada peserta penyuluhan agar melaksanakan senam tera dengan tepat. Tiga tahap kegiatan edukasi tentang hipertensi memberikan informasi, pengetahuan serta keterampilan bagi lansia yang efektif dan menarik dengan berbagai variasi metode dan media penyuluhan. Indikator keberhasilan kegiatan diukur dengan menilai dan membandingkan perubahan pengetahuan dan keterampilan lansia sesudah penyuluhan dengan berbagai variasi metode dan media penyuluhan lebih tinggi dari pada sebelum dilakukan penyuluhan. Luaran kegiatan ini adalah leaflet dan poster tentang 
informasi kesehatan untuk dibagikan kepada peserta penyuluhan dan ditempelkan di wisma tempat tinggal lansia, serta setiap orang lansia mampu mempraktekkan senam tera yang benar pada akhir kegiatan serta adanya peningkatan pengetahuan tentang Hipertensi pada lansia.

\section{PEMBAHASAN}

Tim kesehatan berperan penting sebagai wadah pendidikan kesehatan bagi masyarakat. Pendidikan kesehatan adalah kegiatan belajar pada individu, kelompok atau masyarakat dari tidak tahu tentang nilai-nilai kesehatan menjadi tahu, dari tidak mampu mengatasi masalah-masalah kesehatannya sendiri menjadi mampu (Notoadmodjo, 2012). Program pendidikan kesehatan masyarakat yang komprehensif penting untuk meningkatkan kesadaran dan mencapai kecukupan pengetahuan. Ketika masyarakat terpapar informasi, maka hal tersebut akan berdampak pada peningkatan tingkat pengetahuan dan tingkat kesadaran mereka yang akan ditunjukan melalui perubahan perilaku (Munawaroh \& Nugroho, 2021). Menurut (Istichomah, 2020) dalam penelitiannya tentang pengaruh penyuluhan kesehatan tentang hipertensi, ditemukan bahwa terdapat perubahan pemahaman lansia tentang hipertensi setelah dilakukan pendidikan kesehatan tentang hipertensi sebesar 86\%. (Kilic, 2018) dalam penelitiannya menyampaikan bahwa program pendidikan yang diberikan kepada pasien hipertensi memiliki efek positif terhadap manajemen hipertensi, dan memberikan kontribusi positif terhadap kesehatan pasien, gaya hidup yang meningkatkan, dan untuk penurunan tekanan darah mereka. Hasil penelitian (Khasanah et al., 2019) menyampaikan bahwa terdapat peningkatan tingkat pengetahuan setelah dilakukan edukasi tentang pencegahan dan perawatan hipertensi. Hal tersebut diperkuat dengan pendapat (Aprillia Veranita, 2020) yang menyampaikan bahwa penyuluhan kesehatan mempunyai pengaruh yang signifikan terhadap kepatuhan pola hidup klien hipertensi.

Pendidikan kesehatan hipertensi penting bagi penderita hipertensi supaya dapat merubah pola hidupnya demi tercapainya kehidupan yang sehat dengan melakukan perawatan hipertensi mulai dari pengaturan diit hipertensi, pengaturan istirahat dan aktivitas, berolahraga, mengkonsumsi obat rutin dan memeriksakan tekanan darah secara teratur (Rendi et al., 2017).

Menurut penelitian yang dilakukan oleh (Pangaribuan \& Nurleli, 2020) banyak faktor penyebab terjadinya hipertensi yaitu dengan hasil penelitian pada lansia yang dilakukan 
Di Poloklinik Rumah Sakit Tk II Putri Hijau Medan terdapat Adanya hubungan bermakna antara faktor umur, olah raga dengan tekanan darah penderita hipertensi pada lansia. Salah satu upaya pendidikan kesehatan pada lansia yang mengalami hipertensi adalah dengan mengajarkan senam tera. Senam tera adalah sekumpulan perilaku yang dipraktikkan atas dasar kesadaran sebagai hasil pembelajaran, yang menjadikan seseorang, keluarga, kelompok atau masyarakat mampu menolong dirinya sendiri (mandiri) dibidang kesehatan dan berperan aktif dalam mewujudkan kesehatan masyarakat. Senam tera harus dipraktekkan terutama pada lansia karena pada hakekatnya setiap masalah kesehatan merupakan hasil perilaku, yaitu interaksi manusia (host), dengan penyebab penyakit (agent) dan lingkungan. Hubungan yang tidak seimbang antara host, agent dan environment menyebabkan meningkatnya kasus penyakit di masyarakat, sehingga dengan penerapan Senam tera dalam kehidupan sehari-hari dapat menurunkan tekanan darah pada lansia. Pelaksanaan kegiatan pengabdian masyarakat dengan tema edukasi pelaksanaan senam tera pada lansia untuk menurunkan tekanan darah terdiri dari beberapa tahapan. Pada tahap pertama dilakukan evaluasi awal (post test) dengan memberikan pertanyaan lisan tentang materi Hipertensi dan senam tera pada sasaran penyuluhan yaitu Lansia yang mengalami hipertensi di UPT Pelayanan Sosial Lanjut Usia Binjai dan sebelum kegiatan penyuluhan dimulai. Tujuan tahap ini untuk menilai pengetahuan dan praktek hipertensi (senam tera) yang selama ini telah atau belum dilakukan. Tim Pelaksanan Edukasi senam tera untuk menurunkan tekanan darah pada Hipertensi Melaksanakan Evaluasi awal dengan Memberikan Pertanyaan Lisan pada Lansia di UPT Pelayanan Sosial Lanjut Usia Binjai dan melakukan pengukuran tekanan darah. Pelaksanaan kegiatan tahap ke 2 (dua) adalah penyuluhan dengan metode ceramah dan mempraktekkan senam tera. Ceramah diberikan dengan menggunakan alat bantu media berupa pemutaran musik senam tera. Variasi metode dan pemanfaatan alat bantu media pembelajaran bertujuan agar penyampaian informasi dalam proses pembelajaran lebih efektif.

Keberhasilan dari pendidikan kesehatan dipengaruhi oleh metode dan media pendidikan kesehatan yang digunakan. Metode pendidikan kesehatan ceramah mempunyai kelebihan yaitu penyuluh mudah menguasai responden, relatif mudah, serta teknik ceramah yang baik dapat mendukung tercapainya penerapan dan pemahaman materi yang disampaikan (Pramiputra, 2014). Hasil studi ini didukung oleh penelitian yang dilakukan (Vandana, 2018), dimana terdapat peningkatan pengetahuan pada lansia sebelum dan sesudah dilakukan pendidikan kesehatan dengan metode ceramah sebesar 57\%. Media yang 
digunakan dalam studi ini adalah leaflet sesuai dengan yang sudah dilakukan oleh. Isi informasi pada leaflet dalam studi ini yaitu berupa kalimat dan gambar yang dapat memberikan stimulus pada visual klien dalam proses penerimaan informasi. Hasil studi yang dilakukan (Istichomah, 2020) menunjukan terjadi peningkatan pengetahuan pada kedua klien setelah diberikan pendidikan kesehatan menggunakan metode ceramah dengan media leaflet selama 60 menit yaitu dari pengetahuan cukup menjadi pengetahuan baik. Hal tersebut diperkuat oleh (Khasanah et al., 2019) bahwa terdapat perbedaan antara tingkat pengetahuan sebelum edukasi dengan sesudah edukasi.

Kendala pada tahap ini disebabkan karena fasilitas penyuluhan yang disiapkan tidak dapat digunakan secara maksimal. Kegiatan senam dilakukan dengan menggunakan wireless, speaker.

\section{Kesimpulan}

Setelah dilakukan dan diberikannya edukasi dan demonstrasi senam tera untuk menurunkan tekanan darah pada lansia di UPT Pelayanan Soial Lanjut Usia Binjai dapat disimpulkan adanya peningkatan pengetahuan tentang senam tera untuk menurunkan hipertensi dan lansia mau melakukannya dengan baik. Hal itu ditunjukkan dengan adanya form penilaian evaluasi yang dilakukan kepada lansia dengan mengukur tekanan darah lansia.

\section{Ucapan Terimakasih}

1. Herly Puji Mentari Latuperissa, S.S.TP selaku Kepala UPT Pelayanan Sosial Lanjut Usia Binjai Tahun 2020 yang telah memberikan bantuan selama melaksanakan pengambilan penelitian ini.

2. Suharto, S.KM., M.Kes selaku Direktur Akper Kesdam I/BB Medan

\section{Referensi}

Aprillia Veranita, L. P. R. S. (2020). Peningkatan Kepatuhan Pola Hidup Melalui Penyuluhan Kesehatan Pada Klien Hipertensi. Jurnal Ilmiah Keperawatan Altruistik, 3(2), 38-47. https://doi.org/10.48079/vol3.iss2.66

Eriyanti, E., Widodo, A., \& Jadmiko, A. W. (2016). " Pengaruh Terhadap Tera Tekanan

Penurunan Pada Darah Dengan Lansia Di Hipertensi Kelurahan Lansia Kartasura 
Pabelan." Perubahan Tekanan Darah, 5-11.

Eviyanti, E., Wijayanti, H. N., \& Khadijah, S. (2021). Pengaruh Senam Lansia terhadap Penurunan Tekanan Darah pada Lansia. Jurnal Kebidanan Harapan Ibu Pekalongan, 8(1), 18-23. https://doi.org/10.37402/jurbidhip.vol8.iss1.117

Guèze, M., \& Napitupulu, L. (2016). Trailing forest uses among the Punan Tubu of North Kalimantan, Indonesia. Hunter-Gatherers in a Changing World, 2(01), 41-58. https://doi.org/10.1007/978-3-319-42271-8_3

Istichomah, I. (2020). Penyuluhan Kesehatan Tentang Hipertensi Pada Lansia di Dukuh Turi, Bambanglipuro, Bantul. Jurnal Pengabdian Harapan Ibu (JPHI), 2(1), 24. https://doi.org/10.30644/jphi.v2i1.369

Iswahyuni, S. (2017). Hubungan Antara Aktifitas Fisik Dan Hipertensi Pada Lansia. Profesi (Profesional Islam): Media Publikasi Penelitian, 14(2), 1. https://doi.org/10.26576/profesi.155

Kemenkes RI. (2019). Hipertensi Si Pembunuh Senyap. Kementrian Kesehatan RI, 1-5. https://pusdatin.kemkes.go.id/resources/download/pusdatin/infodatin/infodatinhipertensi-si-pembunuh-senyap.pdf

Khasanah, U., Anwar, S., Sofiani, Y., \& ... (2019). Edukasi Masyarakat Dalam Peningkatan Pencegahan Dan Perawatan Hipertensi dan DM Desa Kaliasin Kecamatan Sukamulya Kabupaten Tangerang. Prosiding Seminar Nasional Pengabdian Masyarakat LPPM UMJ, September 2019, 1-10. https://jurnal.umj.ac.id/index.php/semnaskat/article/view/5432

Kilic, D. (2018). Pengaruh Pendidikan Menggunakan Model Adaptasi Roy pada Manajemen Hipertensi. International Journal of Caring Sciences 11 (1), 333.

Kowalak. dkk. (2016). Buku Ajar Patofisiologi Jakarta: EGC

Kurniasih, I., \& Setiawan, M. R. (2013). Analisis Faktor Risiko Kejadian Hipertensi di Puskesmas Srondol Semarang Periode Bulan September - Oktober 2011. Jurnal Kedokteran Muhammadiyah, 1(2), 54-59.

M. Noor Ifansyah, Herawati, N. D. (2015). Senam lansia terhadap penurunan tekanan darah pada lansia dengan hipertensi. Jurnal $D k, 3(1), 86-93$.

Munawaroh, D. M., \& Nugroho, H. A. (2021). Pendidikan Kesehatan Hipertensi Untuk Penurunan Resiko Komorbid Covid-19 di Pengungsian Ngrajek Magelang. Ners Muda, 2(2), 24. https://doi.org/10.26714/nm.v2i2.6974

Mustofa, F. L., Febriyani, A., Prasetia, T., \& Hasriza, I. A. (2020). Hubungan Karakteristik Dan Aktvitas Fisik Dengan Tingkat Hipertensi Pada Lansia Di Panti Sosialtresna Werdha Natar 2019. Jurnal Medika Malahayati, 4(2), 87-94. https://doi.org/10.33024/jmm.v4i2.2522

Notoadmodjo, S. (2012). Promosi Kesehatan dan Perilaku Kesehatan. Jakarta: Rineka Cipta.

Pangaribuan, \& Nurleli. (2020). Faktor-Faktor Yang Berhubungan Dengan Kejadian Hipertensi Pada Pasien Lanjut Usia Yang Berobat Di Poliklinik Penyakit Dalam Rumah Sakit Tk. Ii Putri Hijau Medan. Journal of Chemical Information and Modeling, 3(9), 11.

Pramiputra et al., (2014). Efektifitas pendidikan kesehatan menggunakan metode ceramah dengan leaflet terhadap peningkatan pengetahuan pencegahan demam berdarah dengue di desa Wonorejo. Diakses dari http://eprints.ums.ac.id/32335/13/2.\%20N ASKAH\%20PUBLIKASI.pdf

Rendi., Wahyuni, T.D., \& Warsono. (2019). Pengaruh Pendidikan Kesehatan Tentang Hipertensi Terhadap Perubahan Perilaku Gaya Hidup Klien Hipertensi di Puskesmas DAU Kabupaten Malang. Nursing News, 2(3).

Sudjana, T. A., Ari, S. N. K., \& Triyani, I. G. . (2015). COPING Ners Journal ISSN: 
2303-1298. Pengaruh Terapi Akupresur Sanyinjiao Point Terhadap Intensitas Nyeri Dismenore Primer Pada Mahasiswi Semester VIII Program Studi Ilmu Keperawatan, 3(2), 7-14.

Tahun, L., \& Ratulangi, S. (2020). Pengaruh Aktivitas Fisik Terhadap Tekanan Darah Pada Usia Lanjut 60-74 Tahun. Jurnal Keperawatan, 8(1), 83-90.

Vandana, M.Y. (2018). Perbedaan Pengetahuan Sebelum Dan Sesudah Penyuluhan Tentang Hipertensi Pada Lansia Di Desa Pesucen Banyuwangi. Jurnal Bahan Kesehatan Masyarakat 2(1). 